\title{
APROXIMACIÓN EPIDEMIOLÓGICA AL PROCESO DE CONTACTO INTERÉTNICO EN EL NORTE DE TIERRA DEL FUEGO
}

\author{
ROMINA CASALI*, MARTÍN H. FUGASSA**, y RICARDO A. GUICHÓN***
}

RESUMEN

Se analizó el proceso de contacto interétnico ocurrido en el norte de Tierra del Fuego durante finales de siglo XIX e inicios del siglo XX. Específicamente, aquellos sucesos vinculados con la misión salesiana de Río Grande, Nuestra Señora de la Candelaria y la población Selk'nam. Mediante el análisis de los registros misionales -diario de la misión, libro de defunciones y libro de bautismos- y de fuentes etnográficas y secundarias, se examinaron las causas de muerte entre los aborígenes, como también aspectos epidemiológicos (edad, sexo, estacionalidad y año de las muertes ocurridas) y su posible impacto en la extinción aborigen. La tuberculosis ha sido la causa de muerte excluyente dentro de la Misión para el período entre 1902 y 1931 y, asimismo, se sugiere como razón para el periodo 1897-1902 (para el cual no existe registro de defunciones). Conforme el comportamiento típico de la tuberculosis tanto en poblaciones occidentales como aborígenes, se propone que la población asilada habría estado compuesta por una mayor proporción de niños, adolescentes y probablemente mujeres. Se discute la incidencia de La Candelaria en el proceso de extinción Selk'nam, a partir de la información obtenida y de los datos demográficos existentes.

PALABRAS CLAVE: Selk'nam, tuberculosis, libros misionales, Misión La Candelaria.

\section{EPIDEMIOLOGICAL APPROACH TO EUROPEAN - NATIVE CONTACT IN NORTHERN TIERRA DEL FUEGO}

\begin{abstract}
European-native contact events during the last part of the 19th century and beginning of the 20th century in northern Tierra del Fuego are examined. Specifically, the events linked with the Salesian mission of Río Grande, Nuestra Señora de la Candelaria and indigenous population. By means of the analysis of missionary records -mission diary, death book and baptisms book- and of ethnographic and secondary sources, the cause of death among the natives was examined. Also its epidemiological aspects (age, sex, seasonal variation and year of death) and its possible impact in Selk'nam extinction are analyzed. Tuberculosis has been the excluding cause of death in the Mission during the period between 1902 and 1931 and we suggest likewise for the period 1897-1902 (for

* Fac. de Humanidades, Universidad Nacional de Mar del Plata, Argentina.

** Depto. de Biología, Fac. de Cs. Exact. y Nat, Universidad Nacional de Mar del Plata / Becario CONICET, Argentina. email: mfugassa@mdp.edu.ar

*** Depto. de Biología, Fac. de Cs. Exact. y Nat., Universidad Nacional de Mar del Plata / Univ.Nac. del Centro / CONICET, Argentina.
\end{abstract}


which there is no death record). According to the typical behavior of tuberculosis disease, either in occidental or indigenous populations, we propose that population sheltered in the Mission was composed by a major proportion of children, teenagers and probably women. We emphasize the thesis that the drastic population reduction of Selk'nam people begun before the emplacement of the Mission and that the 223 deaths reported in La Candelaria were a part of this process, but in an already irreversible context.

KEY WORDS: Selk'nam, tuberculosis, missionary records, La Candelaria Mission.

\section{INTRODUCCIÓN}

El poblamiento humano de la isla grande de Tierra del Fuego se remonta a unos 10.000 años A.P (Massone 1987). En general, se reconocen tres grupos poblacionales a la llegada de los colonizadores, sin que esto implique una aprehensión estática y absoluta de su territorialidad, su historia y su cultura. Los Selk'nam (Onas) ocupaban el interior de la Isla Grande, como cazadores-recolectores dedicados principalmente al aprovechamiento de recursos terrestres, tales como guanacos; los Yámana (Yaganes) se distribuían en la zona del canal Beagle y del cabo de Hornos y los Kawéskar (Alacalufes) a lo largo de los canales de la Patagonia occidental; ambas poblaciones especializadas en el usufructo de recursos marítimos (peces, moluscos y lobos marinos, entre otros).

El descubrimiento del paso austral hacia el Pacífico por Fernando de Magallanes en 1520, promovió el emprendimiento de numerosos viajes al archipiélago fueguino en el marco de la competencia entre los países europeos por el control estratégico de las rutas comerciales y los mercados; también ocurrieron expediciones de carácter científico. En esta etapa, la relación entre aborígenes y europeos se produjo principalmente mediante naufragios y restos materiales que llegaban a las playas, por lo que es conveniente hablar de un período de contactos indirectos (Borrero 1992). Menos comunes habrían sido los contactos cara a cara, sucedidos esporádicamente y entre un pequeño número de personas (Fugassa y Guichón 2004).

La etapa de contactos directos (continuados, permanentes) se inició hacia 1850, cuando los misioneros anglicanos llevaron adelante, desde la Isla Keppel (Malvinas), los intentos por establecerse en la Tierra del Fuego, alcanzando el objetivo en 1870 con el afincamiento de la Misión Anglicana en la actual Ushuaia (Braun Menéndez 1941). En el área continental chilena se promovía el poblamiento de la región con la inauguración del fuerte Bulnes, en 1843, y su posterior traslado a suelos más apropiados, al sitio conocido como Punta Arenosa, donde a partir de 1848 comenzaría a desarrollarse gradualmente la ciudad de Punta Arenas. La misma revistió sucesivamente las características de presidio, puerto libre y sitio de explotación de carbón, oro, lobos marinos, guanacos y avestruces, hasta que en 1877 se dio lugar a la actividad ganadera. Se convirtió así en la dinamizadora de toda la región, incluso luego de que en 1881 los gobiernos de Chile y Argentina imprimieran los límites nacionales (Martinic 1982:42; Bandieri 2005:122).

La historia de la isla puede comprenderse de acuerdo con la interacción que los sucesivos protagonistas establecieron con los aborígenes y entre ellos mismos, según los diversos intereses: navegantes, balleneros y loberos, misioneros, científicos, buscadores de oro, hacendados, políticos y funcionarios. La colonización se inició desde el lado chileno con la explotación de los placeres auríferos hacia 1881 y en segunda instancia con la instalación de estancias destinadas a la cría del ovino, desde 1885. La fundación oficial del primer poblado fueguino, Porvenir, sobrevino en 1894 y en 1896 se estableció la primera guardia policial permanente. Por su parte, el gobierno argentino equiparaba los esfuerzos por la defensa del territorio con la instalación de la subprefectura en Ushuaia, en 1884 y a través de las expediciones que permitieran el conocimiento de la región para su posterior poblamiento y explotación económica. Para 1890, en el extremo norte de la bahía San Sebastián, el rumano J ulio Popper comandaba la producción aurífera y levaba ansias de autoridad, llegando incluso a mantener conflictos con los gobernadores de la isla (Bandieri 2005:189; B elza 1974). Hacia mediados de los noventa, comenzaría también en territorio argentino la empresa ganadera. Fue, entonces, el último cuarto del siglo XIX el que implicó un cambio significativo en el destino de 
las poblaciones aborígenes, a partir del poblamiento efectivo de la región y de las consecuencias de la progresiva actividad económica.

Existen diversos trabajos referidos a la desaparición de los pueblos originarios de Tierra del Fuego, como también numerosos relatos etnográficos que ofrecen datos importantes respecto de dicho proceso y todos coinciden en marcar al contacto interétnico como causa básica del mismo. Para la población Selk'nam, específicamente, estudios previos enfatizan las causas de extinción relacionadas con la llegada de los estancieros y la cría intensiva de ganado lanar, de acuerdo con las necesidades del mercado internacional, como ya se mencionó (Dabbene 1904; Gallardo 1910:98; Massa 1945:325; Gusinde 1951:100; Emperaire y Laming 1954; De Agostini 1956:295; Martinic 1973, 1982:8091, 1990, 2003; Belza 1974:356; Gusinde 1982:820; Massone et. al. 1993:21; Coiazzi 1997:16; Borrero 2001:120; entre otros).

Así, la matanza por parte de los propietarios de tierras e, incluso, de los buscadores de oro habría ejercido un rol importante en la desaparición aborigen. Pero también existieron consecuencias de la ganadería que afectaron indirectamente a los nativos, como el cercado de los territorios, el cuál condicionó el movimiento de los grupos que, alterada su territorialidad, asistieron a un enfrentamiento intraétnico o a la potenciación del ya existente. La competencia y desplazamiento del guanaco, recurso básico de los selk'nam, por parte de las ovejas, habría implicado por un lado la escasez de alimento y otras materias primas y, por el otro, que los aborígenes fueran capturados o asesinados por intentar aprovechar a las ovejas como nueva fuente nutricional. Por otra parte, las autoridades, conjuntamente con los dueños de tierras y los misioneros, llevaron adelante la estrategia de trasladar grandes cantidades de aborígenes a las misiones e incluso a las ciudades como Punta Arenas - aunque en proporciones menores. Algunos autores coinciden en marcar la extinción de la población Selk'nam debido a la diseminación de enfermedades infecciosas como consecuencia de la convivencia en las instituciones religiosas (G allardo 1910:292; Braun Menéndez 1939:187,309; Massa 1945:343; De Agostini 1956:295; Belza 1974:334; Belza 1975:344; Bruno 1981b: 454; Martinic 1982:92; Gusinde 1982:169; García Moro 1992; Borrero 2001:114; entre otros).

Elaborar un análisis minucioso del proce- so de desaparición de la etnia Selk'nam, en procura de comprender cuáles fueron las formas que operaron y el alcance de cada una, es fundamental para establecer aportes que escapen a las especulaciones y los mitos. Es plausible contribuir a este objetivo a partir de enfoques micro, tal como fuera sistematizado por García Moro (1992) para las misiones salesianas. En este trabajo se continúa dicha línea de investigación, incorporando datos y puntos de discusión. Parte de los objetivos será realizar un análisis exhaustivo de la ocurrencia de las enfermedades en la Misión Salesiana La Candelaria y su probable incidencia en la extinción Selk'nam. Asimismo, se espera poder contribuir a la construcción de un panorama epidemiológico para el archipiélago, que pueda ser cotejado con el registro arqueológico, en la medida que aumente la información cronológica y los estudios paleopatológicos del mismo. Se plantea como metodología apropiada el estudio interdisciplinario, a fin de superar las limitaciones de los enfoques unilaterales.

\section{SÍNTESIS DE LA INFORMACIÓN HALLADA EN LOS REGISTROS MISIONALES}

Se efectuó un análisis historiográfico de los registros de la Misión Salesiana Nuestra Señora de $L$ a C andelaria -Río Grande, Tierra del Fuego, Argentina- instalada en 1893 en el marco del ya iniciado proceso de colonización ${ }^{1}$.

El Libro I de Defunciones -años 18971902- se ha extraviado, razón por la que el período correspondiente se ha examinado a través del Diario de la Misión (DLM), Cuaderno I 1896-1904 y la etapa 1902-1931, por medio del Libro II de Defunciones (LD II). Para el lapso de superposición entre ambas fuentes, (27-8-1902 a 1-8-1904) se tomaron los datos del LD II, por ser más completo. Los libros I y II de Bautismos también fueron incorporados al análisis a modo de complemento. Es preciso indicar que la institución concluyó su tarea como misión en 1928, pasando a cumplir desde 1942, entre otras funciones, la de Escuela Agrotécnica (Borrero 2001:117), labor que continua hasta la actualidad.

Se han elaborado tablas y gráficos que sintetizan los datos obtenidos de las fuentes, a fin de observar el comportamiento de las defuncio-

1 Las fuentes fueron obtenidas durante la campaña 2005 en el marco del Proyecto "Ecología Evolutiva Humana en Tierra del Fuego" PICT 4-13889. 
nes según sexo, edad, época del año, causa, distribución por años, entre otros. Como parámetro para el agrupamiento por edades se siguió lo propuesto por Buikstra y Ubelaker (1994:9). Considerando que el perío do cubierto por el DLM carece de información sobre causa de muerte, se comparará el perfil de muertes por edad, sexo y estacionalidad para aquellos años (1896-1902), con el período para el que sí se cuenta con dicha información a partir del LD II (1902-1931). De esta manera se podrá discutir si existen coincidencias entre los perfiles de muerte de ambos períodos y en consecuencia analizar las posibles causas de muerte para los años estudiados mediante el DLM. Debe señalarse que no es posible establecer una relación exacta entre el número de muertes y la población de la misión para cada sexo, edad y estación del año (tasas de mortalidad), por lo que se discutirán las posibles conexiones de los resultados obtenidos a partir del análisis de los registros parroquiales con la información brindada por fuentes secundarias y etnográficas, a fin de estimar la correspondencia entre las defunciones y la población total de la Misión.

EI DLM es un registro en el que aparecen las defunciones en el marco de una enumeración más amplia de acontecimientos. Dependerá de qué misionero realizó la nota, si fueron apuntados los datos referidos a los padres o cónyuge, aunque sí figuran el nombre, el sexo, la fecha y la edad para la mayoría de los casos, no obstante aumenta la cantidad de reportes indeterminados en este aspecto, ya que se hacen presentes las categorías de niño, niña y mujer. Presenta 118 defunciones internas (Tabla 1), de las cuáles 49 corresponden al sexo masculino y 69 al femenino (Tabla 2). No se ha dejado constancia alguna sobre las causas, excepto en tres casos en los que se menciona a la tuberculosis.

Además, esta fuente posee gran impor- tancia ya que se citan tres censos poblacionales (5/6/1900,5/2/1901 y 3/3/1902) lo que podría ser de utilidad para intentar establecer la relación entre las defunciones y la población absoluta para lapsos específicos. Asimismo, del DLM pueden desprenderse aspectos cualitativos que hacen al vínculo religioso-aborigen, al rol de los aborígenes en la misión, a su desplazamiento, a su comportamiento, a la concepción que los religiosos tenían de los aborígenes, etc. A su vez, la información obtenida permite vislumbrar la inserción de la misión en el contexto: su vínculo con las instituciones, con las estancias aledañas, la importancia de la actividad económica, etc.

EI LD II indica para las 118 muertes reportadas (Tabla 1), sexo, edad, fecha, sitio de entierro y sacerdote firmante. En la mayoría de los registros figura el nombre de la persona, de los padres o cónyuge y la causa de muerte. Aparecen también, 13 casos de entierros externos a la misión (vecinos que utilizaron el cementerio de L a Candelaria y casos policiales), que se distribuyen hacia el final del perío do (desde 1919); a su vez, entre 1916 y 1931 se registraron solamente 8 defunciones. Para el período 1902 a 1931, el número total de muertes internas es de 105, de las cuáles 52 corresponden al sexo masculino y 53 al femenino (Tabla 2).

En la mayoría de las oportunidades (68\%) se trata de diagnósticos de tuberculosis pulmonar 0 tisis (Fig. 1). En la Figura 2 se muestra discriminada por edades la relación entre muertes por tuberculosis y muertes totales, es decir, aquellas para las que no se cuenta con datos respecto de la razón de muerte. Se observa que la tuberculosis afectó mayoritariamente al grupo etario entre los 4 y 12 años. El reporte de un único caso de meningitis en un niño de cinco años podría sugerir diferentes etiologías, entre las que se halla la tuberculosis (Benenson 1992:540). Asimismo, las pulmonías comunicadas coinciden con un

TABLA 1. Síntesis de las defunciones registradas en las fuentes analizadas.

\begin{tabular}{lccc}
\hline & Fuente 1: DLM & Fuente 2: LD II & Total \\
\cline { 2 - 3 } Período & $12-12-1896$ a 26-8-1902. & 27-8-1902 a 18-10-1931. & \\
\cline { 1 - 3 } Defunciones de externos & 8 & 13 & 21 \\
Defunciones de internos & 118 & 105 & 223 \\
Total & 126 & 118 & 244 \\
\hline
\end{tabular}

DLM: Diario de la Misión. LD II: Libro de Defunciones II. 
TABLA 2. Detalle del número de muertes ocurridas en la Misión en ambos períodos y discriminadas por sexo.

\begin{tabular}{lccc}
\hline & \multicolumn{2}{c}{ Sexo $(\%)$} & Total \\
\cline { 2 - 3 } & Masculino & Femenino & \\
Período I & $49(41.53)$ & $69(58.47)$ & $118(100)$ \\
Período II & $52(49.52)$ & $53(50.48)$ & $105(100)$ \\
Total & $122(54.70)$ & $101(45.29)$ & $223(100)$ \\
\hline
\end{tabular}

cambio momentáneo del sacerdote a cargo de la notificación, por lo que la nominación pudo deberse tan sólo a qué tan familiarizado estuviera el mismo con el comportamiento de la enfermedad. No debería excluirse, entonces, la contingencia de cuadros de tuberculosis pulmonar. Entre las causas de muerte, el segundo lugar lo ocupa la categoría Sin Datos (Fig. 1), lo que no implica necesariamente, la existencia de otras enfermedades ya que se trata de omisiones. Además, el rango etario que contiene una mayor proporción de casos sin consignar la causa de muerte es aquel entre 0 y 3 años (Fig. 2), lo que podría deberse a las dificultades de los misioneros para diagnosticar la tuberculosis aguda en los lactantes o simplemente la falta de interés en conocer la etiología. Algo similar podría ocurrir con los reportes de tos convulsa, los cuáles corresponden a niños de dos meses de edad.

Para la tuberculosis, la morbilidad varía en los diversos grupos etarios según el sexo, origen poblacional y, fundamentalmente, situación socio-económica (Daniel 1981:37), resultando difícil identificar un único motivo para el compor-



Fig. 1. Causas de muerte registradas en el LD II. TB: tuberculosis, SD: sin datos, P: pulmonía, TCV: tos convulsa, C: paro cardíaco, $\mathrm{M}$ : meningitis. tamiento de la enfermedad. En general, la susceptibilidad es mínima en niños mayores de 3 años y la incidencia es especialmente alta en ancianos debido a la reactivación de antiguas infecciones (Benenson 1992:543). Diversos estudios realizados sobre poblaciones aborígenes han demostrado incidencias diferentes a las halladas en poblaciones occidentales. Comparativamente, en aborígenes, se ha reportado una mayor incidencia en menores de 15 años y una menor incidencia en adolescentes y adultos jóvenes (Canadan Lung Association 2000:19; Canadian Tuberculosis Committeé 2002; Kunimoto et al. 2004). Asimismo, entre los aborígenes -como suceden en poblaciones occidentales- la incidencia crece en adultos mayores (Beilby et al. 1990). Para la Misión La Candelaria, el mayor número de muertes sucedió en el rango etario de 4-12 años (Fig. 2), lo que coincide con los resultados expresados en las líneas anteriores.

El reducido número de defunciones entre adultos mayores de 50 años (Fig. 2), podría haber sido el producto de una población asilada con un escaso número de adultos y ancianos. Esto

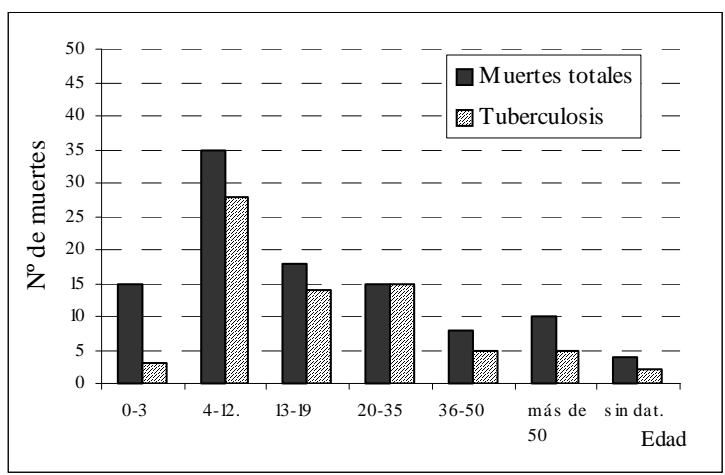

Fig. 2. Incidencia (por edades) de las muertes por tuberculosis sobre el total de muertes reportadas entre 1902 y 1931 (LD II). 
podría interpretarse como el resultado de la resistencia de los adultos a refugiarse en la Misión, o bien como consecuencia de una población natural con una estructura de edades alterada por otros contactos previos y contemporáneos al emplazamiento de la Misión. No puede desecharse la hipótesis de una concurrencia de ambas causas. Borrero (2001:114) menciona cómo en el momento álgido del enfrentamiento entre los Selk'nam y los estancieros se implantó un patrón general, que fue el de matar a los hombres y deportar a las mujeres y niños a la isla Dawson. La falta de información detallada sobre la composición en edad y sexo de la población albergada inhibe mejores inferencias.

\section{ANÁLISIS DE LAS CAUSAS DE MUERTE PARA EL PERÍODO I (1896-1902)}

Como se indicó, para los años 1897-1902 el registro carece de detalles sobre las causas de las muertes sucedidas dentro de la Misión. En contraparte, para el lapso 1902-1931 sí se cuenta con dicha información. La comparación de los perfiles de muerte entre ambos períodos puede ayudar a comprender las posibles causas de muerte durante los años 1897-1902, aunque debe tenerse precaución ya que no es posible contar con las tasas de mortalidad respectivas. Aunque el número de muertes para cada rango etario es relativo a la población existente para cada período, en la Figura 3 puede apreciarse que la cantidad de muertes para cada grupo etario guarda una proporción, entre estos, similar en ambos períodos.

La comparación del perfil de muertes por sexo entre ambos períodos no refleja diferencias importantes (Tabla 2). Estudios realizados sobre otras poblaciones sugieren que la incidencia de la enfermedad en ambos sexos es distinta al aumentar la edad de los individuos (Canadian Lung Association 2000:19; Daniel 1981:37-39). Sin embargo, en el perfil de muerte por sexo de $L a$ Candelaria (Tabla 2) no sobresalen contrastes. Posiblemente, como se sugirió, la Misión habría acogido mayormente a lactantes, niños y jóvenes, en los cuáles la tuberculosis no se manifiesta con incidencias diferentes para ambos sexos. También pudieron haber existido diferencias en la proporción de varones y mujeres asilados. Nuevamente, la imposibilidad de obtener tasas de mortalidad, en este caso para cada sexo impide conclusiones más precisas.

Si bien García Moro (1992) sostiene que no existe correlación significativa entre las defunciones anuales y las temperaturas ni con las precipitaciones medias, la distribución de las muertes en el año puede ser útil para una discusión en función de las posibles causas. Podría argüirse que se trata de dos factores distintos, la estacionalidad de las muertes y las razones de la misma, pero lo cierto es que se observa un aumento del número de muertes para la primavera (específicamente agosto-noviembre) y un decrecimiento hacia el verano, que alcanza su máxima en el otoño (Fig. 4). Ello se puede relacionar con el hacinamiento y el stress nutricional sucedido durante los meses más rigurosos que podrían haber propiciado la reactivación de focos tuberculosos en adultos e infecciones primarias en niños y jóvenes. La tuberculosis ocasionalmente produce enfermedad en el curso de una infec-

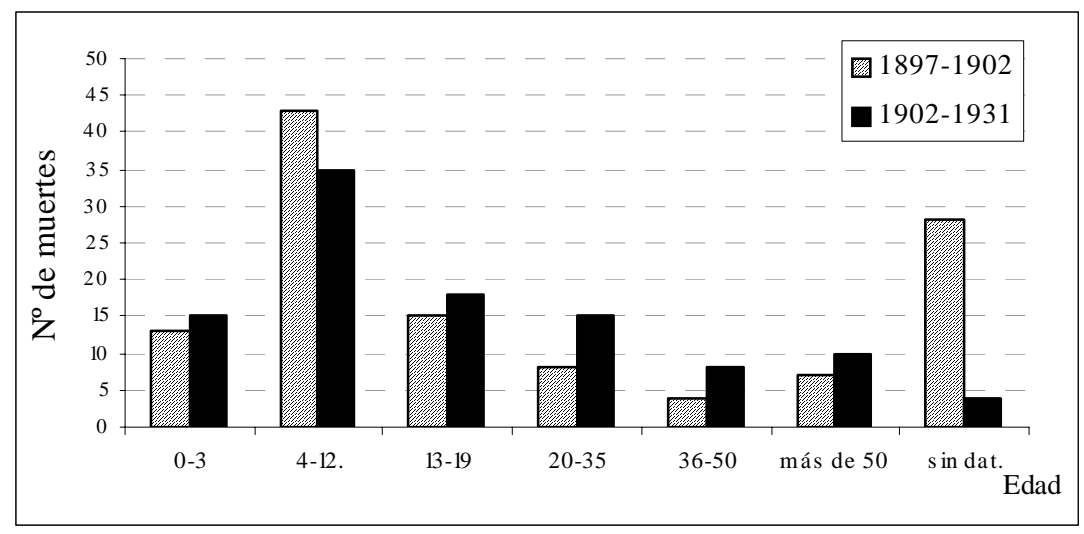

Fig. 3. Número de muertes por edades para ambos períodos 


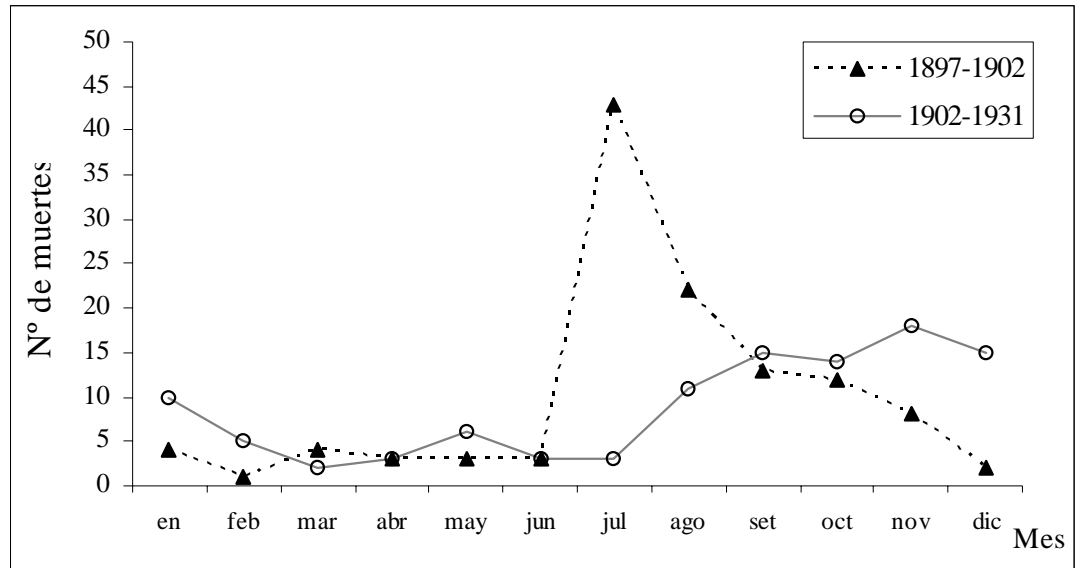

Fig. 4. Distribución de las muertes por mes comparando ambos períodos.

ción inicial y generalmente permanece latente (Benenson 1992:540). Sin embargo, en poblaciones aborígenes pudo haber existido una mayor incidencia por infecciones primarias o iniciales (Daniel 1981:35). Asimismo, en los individuos más jóvenes aumenta la frecuencia de que infecciones primarias provoquen enfermedad activa y muerte (J ohnston 1993:1060).

Si se atiende al mes de julio (Fig. 4), puede apreciarse que el aumento en el total de muertes se debe fundamentalmente a lo registrado en el DLM, lo que contrasta claramente con lo referido en el LD II. Ello se debe a la alta mortandad ocurrida en julio de 1897, la cual se explicará más adelante. Ambos períodos muestran, entonces, un comportamiento similar también en cuanto a la estacionalidad de las muertes.

En conclusión, el análisis del número de muertes por edad, sexo y estacionalidad entre ambos registros (DLM y LD II) sugiere que las características epidemiológicas de la Misión habrían sido similares en los dos períodos examinados. Por consiguiente, es posible sostener que la causa de muerte para el período cubierto por el DLM ha sido principalmente la tuberculosis. Debe recordarse que sólo existe una división arbitraria entre ambos períodos, consistente en la calidad relativa de las fuentes disponibles.

Cabría acotar que en Europa, durante el siglo XIX, la tuberculosis era una de las causas principales de muerte. En los centros urbanos de América la enfermedad también alcanzaba niveles altos, con tasas de mortalidad que llegaban a 618 cada 100.000 habitantes en Filadelfia, Estados Unidos (J ohnston 1993:1063). Hasta mediados de siglo, la tuberculosis era denominada de

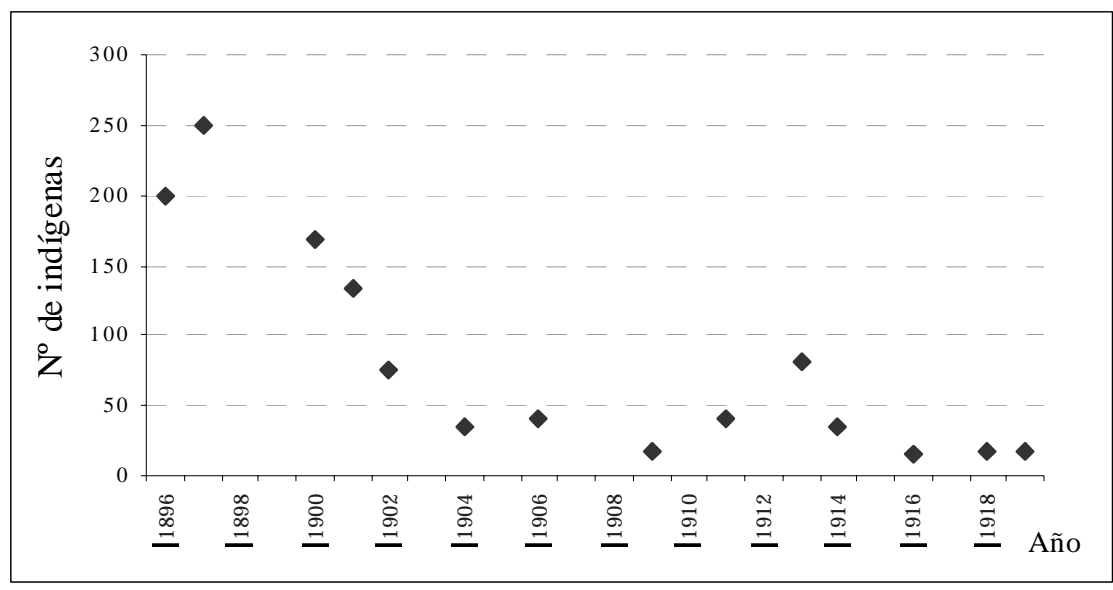

Fig. 5. Población asilada en la Misión La Candelaria entre 1897 y 1920. 
diversas formas y cada una significaba una enfermedad distinta: tisis (tuberculosis pulmonar), escrófulas (tuberculosis de ganglios linfáticos del cuello) y lupus vulgaris (tuberculosis con lesiones de piel), entre otros (idem:1062; Buikstra 1981:2). En la Misión, aunque se ha empleado el término tisis, simultáneamente se ha registrado el término tuberculosis lo cual sugiere que han prevalecido las manifestaciones pulmonares de la enfermedad.

\section{LA POBLACIÓN SELK'NAM EN LA MISIÓN LA CANDELARIA}

En este apartado se implementa una sucinta descripción del devenir de la población Selk'nam en la Misión, en un intento de aproximación a su tamaño para los distintos años. En la Figura 5 se expresan las cantidades de aborígenes presentes en La Candelaria según dos fuentes: por un lado, la obra de Bruno (1981) quien se ocupa de citar diversas cartas de los misioneros en las que se hacen explícitas las cifras de los aborígenes residentes en $\mathrm{L}$ a Candelaria y por otra parte, los censos poblacionales registrados en el DLM.

En noviembre de 1893 los misioneros iniciaron la construcción de la capilla, el depósito, el galpón de madera y un dormitorio. En marzo de 1894 sucedió el primer contacto cuando aparecieron los primeros abo rígenes, tres sujetos vestidos como cristianos y detrás de ellos otros seis indígenas seguidos de las mujeres y niños, y de una multitud de perros; los hombres con sus arcos y flechas en ademán defensivo, a la derecha de los misioneros [...] la desconfianza de todos se transformó en ruidosa algarabía cuando, tras palabras amistosas comenzó el reparto de frazadas y galletas (Bruno 1981a:480-481). Las mujeres se encargaron de levantar los toldos a 200 metros de la casa, mientras hombres y niños merodeaban observándolo to do y preguntando. Elementos tales como la vestimenta, la cantidad de perros, el ademán defensivo y tal vez la desconfianza de los aborígenes dejan entrever un previo contacto de los Selk'nam con los colonizadores.

Algunos días más tarde ya sobrepasaban los 350 aborígenes (Paesa 1976:14) - según las citas de Bruno eran 500 (1981a:480)- y el misionero Beauvoir comentaría luego que desde esa fecha nunca más pudimos reunir tantos indígenas [...] ni aún cuando tres años después estuvo ya del todo constituida la Misión de Río Grande (Bruno 1981a:481). Aquellos habrían llegado en sólo dos oportunidades, diferenciadas por la pertenencia al grupo de los Selk'nam del sur o del norte. De hecho, los religiosos relatan como su acción pacificadora fue la que puso coto al potencial enfrentamiento entre ambos, el cual se materializó una vez alejados de la Misión, incluyendo la muerte de algunos (Paesa 1976:14). Como marca Chapman (1998:84), los Selk'nam se conectaban a través de parentelas que tejían redes de relaciones entre toda la población de la isla, al tiempo que las familias y los linajes determinaban la pertenencia a un mismo haruwen 0 territorio. Si bien, como ya se dijo, no debe abogarse por una aprehensión estática del desenvolvimiento de los pueblos originarios fueguinos y los haruwen no eran unidades cerradas o células, no debe olvidarse que los Selk'nam constituían pequeños grupos formados por unas pocas familias, las que en conjunto no sumaban más de veinticinco o treinta personas (idem: 95). Un fuerte concepto de territorialidad impelía al respeto por los límites geográficos preestablecidos y la trasgresión de los mismos podía producir el enfrentamiento entre dos grupos (Massone et. al. 1993:15; Chapman 1998:94; Borrero 2001:100). A parentemente, los Selk'nam conciliaban la rigidez del haruwen con la flexibilidad de la parentela, a fin de asegurar una buena convivencia y un eficiente aprovechamiento de los recursos. Pero, que en 1894, llegaran a la Misión al menos 350 indígenas en sólo dos ocasiones, no puede sino invitar a la reflexión acerca de las posibles alteraciones sufridas por la población con anterioridad a la llegada de los misioneros.

Para los primeros tiempos, los testimonios indican la no-permanencia de los aborígenes en la Misión como conducta habitual. A los temores de una situación de contacto interétnico, pueden sumarse las características de la Misión entre el comienzo de su construcción en diciembre de 1893 y mediados de 1896 aproximadamente. Se trataba de una pequeña capilla, alrededor de la cuál se establecían las familias aborígenes en sus toldos, permanecían algunos días, aceptaban alimentos de los misioneros, interactuaban con ellos y luego se retiraban. Lentamente se fueron construyendo habitaciones y para el momento del incendio (12-12-1896) ya existían una casa para las hermanas y sus niñas y otra para los salesianos y sus niños (Bruno 1981b:458). De los relatos de los misioneros puede inferirse que durante estos 
tres primeros años la relación de los aborígenes con la Misión revestía ciertas particularidades. En los dos primeros años, entonces, habría primado el temor de los indígenas: en junio de 1895 una de las hermanas de María Auxiliadora comentaba que llegaron muchos indios; pero acamparon a cierta distancia de la misión [...] pasamos por las chozas dando a todos galletas para poderlos contar y saber cuántos eran, pero los indios escondieron a varios de sus hijitos e hijitas (Bruno 1981b:435); al cabo de un par de días los huéspedes se acercaron: hoy nos visitaron los indios, con excepción de niñas y niños, por temor -se ve- de que se los quitemos para tenerlos en casa (ibidem). Con el transcurso de los días, los religiosos pudieron comenzar con sus tareas de evangelización, enseñanza y aseo de los aborígenes, al tiempo que éstos aceptaban gradualmente aquellas prácticas e, incluso, las del trabajo: Hoy -21 de junio de 1895- los indios con alguna india comenzaron a hacer algún trabajo: después les dimos galleta, para que entendieran que debían ganarse la comida (idem:436); Las mujeres comenzaron a hilar la lana el 14 de enero de 1896 (idem:437). Se ha remarcado la cualidad aprensiva de los Selk'nam respecto a su permanencia en la Misión, a fin de considerar el posible alcance del contacto, pero no debería desestimarse la movilidad propia de aquella etnia.

Que con el correr de los meses, la interacción entre los Selk'nam y la Misión, mientras duraba su estadía en los alrededores, fuera cada vez más fluida y constante, no invalidaba el hecho de que cuando lo creyeran oportuno aquellos se retiraran a los bosques. Todavía para fines de 1895 los sacerdotes mencionaban cómo los indios [...] ya a menudo nos visitaban [...] formando sus tolderías a dos o tres cuadras de la Misión; se detienen poco -unos quince o veinte días los más- pero van y vienen continuamente (Bruno 1981a:482-483.). Sólo a partir de 1896 los aborígenes se atrevieron gradualmente a trabajar y a convivir con los misioneros: hoy -1 de septiembre de 1896- reunimos a las viudas y casadas que tienen el marido lejos para animarlas a vivir juntas en la casita hecha para ellas. Vinieron todas, pero alguna huyó durante la noche (Bruno 1981b:437).

El edificio de la Misión se incendió el 12 de diciembre de 1896, perdiéndose todo. Para ese momento, según el Padre Griffa (Bruno 1981b:438) ya teníamos asilados 165 indios, sin contar los nómadas de siempre, indecisos de cuan- do iban a quedarse con nosotros. Respecto de la cantidad de aborígenes al momento del incendio podría agregarse que en el DLM figuran 200, cifra que coincide con la ofrecida por Coiazzi (1997:19). El 18 de diciembre, 6 días después del incendio, llegaron 15 aborígenes más, que el comisario sacó de los toldos, según se expresa en el DLM. Podría presumirse, entonces, que no necesariamente los aborígenes habitaran todos juntos en una vivienda, por lo que no queda muy claro a que se referían los salesianos cuando utilizaban la categoría Asilados. Tal vez existiera cierto grado de hacinamiento, pues como se expuso, hacia mediados de 1896 los aborígenes comenzaron a convivir en el edificio de la Misión, pero esto no es necesariamente incompatible con la imagen de otros acampando en sus toldos en las cercanías del establecimiento. Además, la convivencia diurna era concreta, ya que los relatos transmiten la imagen de los aborígenes juntos por los corredores del edificio, los patios, los salones - la Capilla. Q ueda claro que la situación de contacto era precisa y por lo tanto las posibilidades de contagio de enfermedades también.

Para el año 1897 no se cuenta con información en forma de censo poblacional, pero es plausible incorporar 92 aborígenes que, como se anotó en el DLM, llegaron a la Misión durante los primeros 5 meses. Si bien 39 indígenas fueron acercados por el mayordomo de los Menéndez, para otros 50, el DLM indica hoy llegaron de vuelta unos 50 indios, por lo que probablemente se tratara de aborígenes que ya habían estado en la Misión, por ejemplo entre los 200 que figuran para el momento del incendio, por lo que no valdría una simple sumatoria.

Podría ser que la inicial actitud de incertidumbre de los indígenas, se convirtiera en estrategia de resistencia, de la cual dan parte tanto Gusinde (1982) como Gallardo (1910). Los aborígenes casi no se apartan hoy de los alrededores del lago Fagnano, región boscosa y montañosa [...] donde encuentran todo lo que necesitan para vivir y sobre todo lugares no frecuentados por su enemigo el hombre blanco (G allardo, 1910:119). En la obra de Gusinde se aprecia como los hechiceros Selk'nam eran conscientes de su impotencia ante las enfermedades ajenas a su población y cómo debían rendirse frente a tales epidemias, carentes de saber y poder ( $G$ usinde 1982:697, 702). Era este conocimiento el que impelía a los selk'nam a refugiarse en las zonas aledañas al lago Fagnano, dónde a su vez halla- 
ban la tranquilidad indispensable para desarrollar su vida espiritual (idem:682, 810). También Borrero (2001:80) y Martinic (2003:23) aluden a esta situación, como estrategia consciente aunque infructuosa, como única alternativa al cercado de los territorios, respectivamente. Asimismo, en el relato de Dabbene (1904) se hace expresa la respuesta de los Selk'nam a la persecución de los colonos, de retirarse a los bosques y llanuras del interior [...] siendo casi imposible sorprenderlos en sus bosques. Los mismos religiosos admitían las privaciones que los aborígenes sentían al permanecer en la Misión (Bruno 1981b:451-455), e incluso eran conscientes de los peligros que implicaban las enfermedades traídas por el blanco (Bruno 1981c:432). Monseñor Fagnano reconocía como los indios que tenemos en la misión de la Candelaria disminuyen todos los años, abatidos por la tuberculosis y quizá por la falta de aire, habiéndoseles construido casas demasiado cerradas. Además en el terreno que ocupan no abunda la leña como ellos la desean (Bruno 1981b:454).

EI DLM marca con qué frecuencia los aborígenes se alejaban de la Misión, permanecían meses en los bosques y regresaban; como también se hace mención a indios que huyen, a indios recién llegados que se van y a cómo los que van llegando son ya conocidos por algún misionero o pariente cercano de aborígenes que ya conocían la Misión. Una de las características de la Misión La Candelaria era justamente que, por su ubicación, permitía a los indígenas conservar cierta libertad de retirarse a los bosques, en contraposición a lo que ocurría en la Misión San Rafael de la isla Dawson (Borrero 2001:69; Bruno 1981b:452; García Moro 1992).

El censo interno del 1-1-1904 marca la presencia de 35 aborígenes, de los cuáles 11 eran menores; el 6-5-1904 en el DLM se menciona la presencia de sólo seis niños, mientras que el 107-1904 el sacerdote escribía: de niños internos tenemos sólo y único Guillermo. Durante el año 1909 no existe registro de muertes. Aparentemente, el despoblamiento de la Misión llegaba a su máximo con apenas una docena de indios, 5 mujeres y una niña para febrero de 1909. Coincidente con ello y en función de la permanencia de los aborígenes en zonas alejadas, los misioneros emprendieron la búsqueda de relictos selk'nam (Bruno 1981b:455). El período 19161931 es claro por la escasa presencia de aborígenes y por el casi nulo registro de defunciones (Fig.
6). Dichos años habrían estado signados por el funcionamiento de las misiones volantes, iniciadas hacia 1910, con base en río Fuego y lago Fagnano y la consecuente concentración de la actividad evangelizadora en el constante recorrido de la isla por parte de los misioneros. EI Cuaderno II de Bautismos recoge las ceremonias efectuadas en río Fuego, cabo S. Inés, cabo S. Pablo, Estancia $\mathrm{H}$ arberton e interior de la isla en general, entre 1910 y 1921. Según Borrero (2001:72), desde el año 1925 en adelante, la vida de los Selk'nam se desarrolló básicamente en las estancias y, finalmente, en los pueblos de El Porvenir, Río Grande y Ushuaia. Algunos se trasladaron al continente, a Punta Arenas o a Río Gallegos, y hasta hubo quien llegó a la provincia de Buenos Aires. Si bien no eran muy afectos a las labores pastoriles, gradualmente se fueron incorporando a la escena social como mano de obra, algunos con posterioridad a la instrucción tomada en las misiones. Los eventos posteriores son simplemente una crónica de sucesivas desapariciones, cada una llevándose un porcentaje mayor de la cultura Selk'nam (ibidem).

En cuanto a los bautismos analizados, éstos corresponden al Cuaderno I dónde figuran las ceremonias efectuadas en la Misión. Se propone aquí que la información demográfica extraíble de dicha fuente es incompatible con los censos del DLM y con el número de defunciones reportadas (ya que también se consignan actos llevados a cabo fuera de la Misión, ya sea en estancias aledañas o en campamentos indígenas), por lo que demuestra ser impropia para una sólida aproximación demográfica, tal como fuera propuesta en otros trabajos. Empero, de la misma ha sido factible obtener detalles vinculados con la movilidad de la población Selk'nam y con otras facetas del contacto interétnico. Por ejemplo, inmediatamente después de la llegada en 1897 de los 50 aborígenes -de los que se reseñó en párrafos anteriores-, sólo se dieron 17 bautismos de adultos, dejando incertidumbre acerca de si el vínculo de los selk'nam con la Misión era tan simple como para ser expresado en términos de estabilidad, de arribo y permanencia. Además, se suscitaron casos de personas bautizadas en la Misión y que residían allí, pero que al tiempo, el registro del nacimiento y bautismo de su hijo fue efectuado en una de las estancias vecinas. A la inversa, se inscribieron bautismos de nacimientos aparentemente sucedidos en la Misión, pero años más tarde el padre aparece como trabaja- 
dor en una estancia. Como se dijo, desde 1910, la totalidad de los bautismos fueron efectuados en el interior de la isla, a partir de los recorridos de los misioneros.

\section{EVOLUCIÓN DE LA MORTANDAD EN LA MISIÓN}

En julio de 1897, en un lapso de 20 días se registraron 34 defunciones (Fig. 4 y 6). Esta situación particular tal vez pueda ser explicada teniendo en cuenta que se trataba de una época del año en la que las temperaturas alcanzaban los -11 o dentro de la habitación (DLM) e incluso los sobrepasaban. Por otra parte, entre el momento del incendio y el 6-11-1897 en que ocurrió el traslado a la nueva casa con las pocas chapas de cinc medio quemadas se habían construido una vivienda para las hermanas y sus indias y otra para los salesianos y los suyos (B runo 1981b:438). Desde ese día y durante cinco meses, tanto las Hijas de María Auxiliadora y sus indiecitas, como los misioneros vivieron bajo carpas y chozas construidas con planchas de zinc averiadas por el siniestro (Massa 1945:341). Los religiosos hacen alusión a la coexistencia en un pobre galpón y a la desesperación de no saber cómo vivir si la Providencia no nos socorre, este invierno moriremos todos de hambre y de frío (Bruno 1981b:43839). A su vez, Monseñor Fagnano menciona para marzo de 1897 -tres meses después del incendiola presencia de 250 aborígenes, entre los cuáles se contaban pupilos 48 niños y 42 niñas (ibidem). No sería arriesgado conjeturar acerca de la convivencia de una considerable cantidad de aborígenes con características de hacinamiento, el que habría sido un factor de importancia en las defunciones sucedidas durante el mes de julio de 1897. Considerando a la tuberculosis como la principal causa de muerte entre los indígenas de la Misión, vale acotar que el rol del hacinamiento en la diseminación de dicha enfermedad ha sido primordial durante el siglo XIX en todo el mundo (Vynnycky y Fine 1999).

Existe un bajo número de muertes reportadas entre los años 1898 y 1899 (Fig. 6). Si se atiende a lo registrado en el DLM, habría que considerar que para esos años tan sólo fueron utilizadas 44 páginas, mientras que, por ejemplo, para un solo año - 1900- se emplearon 120. Por otra parte, la información brindada por el DLM para los años 1898 y 1899 se relaciona casi en su totalidad con aspectos organizativos de la Misión o ligados a las actividades económicas: compra y venta de animales, trabajos propios de la ganadería, llegada de embarcaciones con distintos elementos para el sostenimiento de la Misión, salida de lana y de cueros, relación comercial con estancias vecinas, etc. Una posible inferencia podría ser que más allá de la cantidad de aborígenes asilados, el interés de los religiosos se centrara en el registro de la actividad ganadera que, por otra parte, se encontraba en pleno auge en toda la isla de Tierra del Fuego (Martinic 1990). Asimismo, entre 1897 y 1898 se exhiben bajos niveles de bautismos (Libro I de Bautismos), Io que estaría reforzando la tesis antes mencionada o podría ser un indicador de la ausencia de aborígenes en la Misión. Recordemos que para marzo de 1897 se contaban aparentemente 250 aborígenes, que el censo del 5-6-1900 informa sobre 168 y que en dicho perío do se reportaron 49 defunciones. Estas cifras nos brindan una idea general de la movilidad de los aborígenes y de cuántos podrían haberse encontrado en la Misión para los años 1898-1899, aunque no especifican si existieron defunciones que no se registraron o se trató de un lapso con bajo nivel de mortandad.

Se observa una concentración de defunciones registradas en el período 1900-1902 -en tres años ocurrió el $44.39 \%$ del total de muertes de los 34 años analizados- y a partir de 1903 un decrecimiento precipitado (Fig.6). A su vez, la Figura 5 evidencia una tendencia similar en términos demográficos, con una concentración de población aborigen residente en la Misión para los mismos años (excluyendo 1896, cuyas características ya fueron analizadas). Lo transcurrido a partir de 1903 debe vincularse más a una reducción del número de aborígenes que a una mejora en el nivel de salud de los mismos. Del estudio del DLM resulta evidente que el despoblamiento causado por los fallecimientos no fue compensado por repoblamientos, lo que podría explicarse como una respuesta de evasión de los aborígenes a las consecuencias del contacto en la misma. Asimismo, dicho despoblamiento pudo relacionarse con otros procesos de contacto (estancias, policía, etc.) cuya consecuencia directa fuera la reducción de la población aborigen en el territorio natural.

Existió un aumento de defunciones entre 1911 y 1916 (Fig. 6). Coincidentemente, en el diario deja de registrarse solo el concepto de O na y comienzan a observarse también los de Indios 


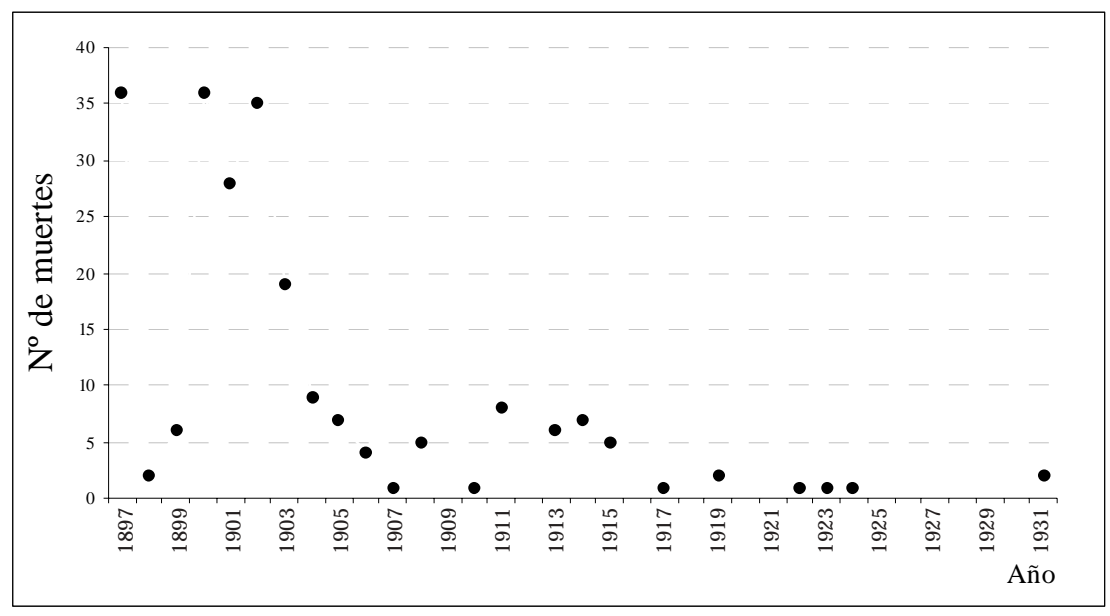

Fig. 6. Total de muertes por año en la Misión Salesiana La Candelaria (1896-1931).

Fueguinos, Indígena o Alakalufes. Los documentos históricos, por su parte, indican: En 1911 (...) se optó por abandonar la isla Dawson, llevando los restantes indígenas a la Misión La Candelaria (...). Con los recién llegados - unos 40 entre chicos y grandes- la misión de la Candelaria cobró nueva vida (Bruno 1981c:429). Así, puede comprenderse como la población de la Misión aumentó repentinamente en 1911 a partir de la llegada de aborígenes provenientes de la Misión Salesiana de San Rafael que había funcionado en la Isla Dawson (Chile) entre 1889 y 1911, momento en que se produjo su cierre definitivo.

\section{LA MISIÓN SALESIANA EN EL PROCESO DE EXTINCIÓN SELK'NAM}

La mayoría de los exámenes aquí revistados, lo mismo que las fuentes etnográficas, esgrimen la relevancia de los contactos entre los selk'nam y los colonizadores. Para futuros trabajos será preciso elaborar un esquema de análisis exhaustivo de cómo fueron los distintos tipos de contacto, al tiempo que intentar evaluar la incidencia de cada uno de ellos en la desaparición de dicha etnia. Cabe aquí la mención de cómo diversos autores coinciden en señalar una primer etapa de enfrentamientos violentos, matanzas y deportaciones, fundamentada en la instalación de los hacendados y el auge de la actividad ganadera y -aunque no tan próspera- la extracción de oro (1890-1900) (Bridges 1886; Dabbene 1904; Gusinde 1951:102; Martinic 1973, 1982, 1990, 2003; Massone et.al. 1993:21; Borrero
2001:59; entre otros). En la Isla Dawson, la labor misionera salesiana comenzó en 1889 con la instauración de la Misión San Rafael y concuerda con el momento de deportaciones: entre 1892 y 1895, por ejemplo, se trasladaron más de 380 Selk'nam (Braun Menéndez 1939:308). Martinic (1973) sugiere que el total de indígenas Selk'nam deportados durante los años de funcionamiento de dicha misión, ascendería a 800. Por otro lado, a partir de 1900 se habría dado una notoria incorporación a la Misión La Candelaria, lo que se ajusta al aumento de las defunciones para el período. En forma paralela, los aborígenes habrían ingresado a las estancias como mano de obra, para gradualmente retirarse a las zonas alejadas de la presencia del blanco.

Para finalizar, entonces, se esbozarán mínimas acotaciones a la discusión respecto de la incidencia de la mortandad en la Misión La Candelaria en la extinción de la población Selk'nam. El proceso de disminución poblacional ha quedado registrado a través de las apreciaciones realizadas por diferentes observadores como Bridges, Gusinde, De Agostini, Popper, Segers, Coiazzi, Dabbene, Gallardo, B ridges Lucas y Zenone, entre otros. Entre las estimaciones que se han efectuado en función del tamaño poblacional de los selk'nam para el momento del inicio de la colonización (1880), los datos utilizados con mayor frecuencia son los expuestos por Gusinde (1982:135), quien propuso la cifra de 3500-4000 individuos para toda la isla y por Bridges (1886), quien estimó en 2000 individuos la población total. Por otro lado, a partir de modelos demo- 


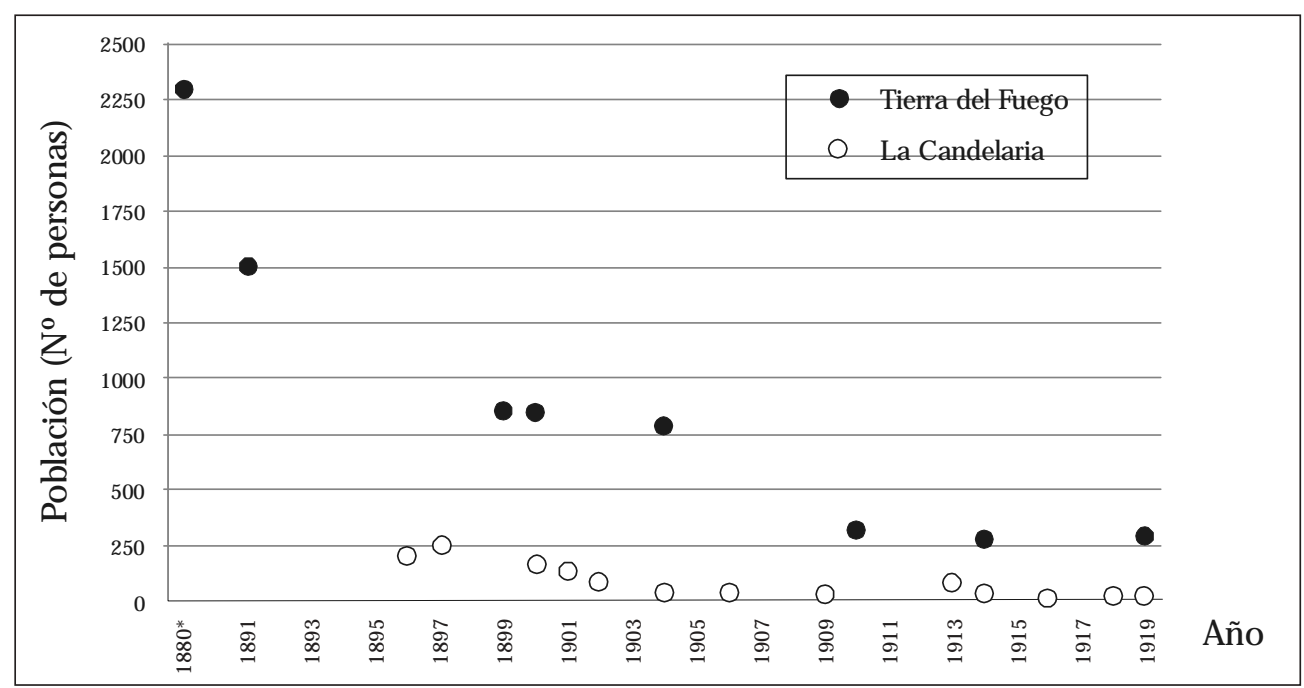

Fig. 7. Población Selk'nam a través del tiempo. Registros para toda la isla grande de Tierra del Fuego ( ) y para La Candelaria (o). (*): cifra promedio para el período anterior al año 1880.

gráficos, García Moro et al. (1997) plantearon la cantidad de 1500 indígenas. Si bien no puede establecerse una cifra precisa, probablemente el tamaño poblacional previo al contacto pudo tener una dimensión intermedia (alrededor de 2400 individuos). Cabe recordar que el censo oficial de Chile advertía sobre la presencia de unos 1500 aborígenes únicamente en el sector de ese país para el año 1895, diez años después del inicio de la actividad ganadera (Martinic 1982:209). A su vez, Martinic (1973) propone para el sector chileno la cifra de 2000 Selk'nam en el año 1881 y 1500 en 1893, momento en que se instaló la Sociedad Explotadora de Tierra del Fuego, acto que predispuso el comienzo de la rápida extinción Selk'nam, según el autor. Partiendo entonces de un promedio entre las mencionadas estimaciones demográficas, se aprecia que la disminución poblacional se habría iniciado antes del emplazamiento de la Misión La Candelaria (Fig. 7).

Se ha generalizado sobre el efecto nocivo de las misiones en las poblaciones aborígenes fueguinas y no es plausible dejar al margen de esta apreciación lo sucedido en La Candelaria. Otros autores han puesto específicamente énfasis en la hipótesis que considera la elevada mortalidad, fundamentalmente debida a enfermedades de tipo infeccioso, fue la causa más directa de la extinción de los onas (García Moro 1992). Sin embargo, considerando la aparente evolución demográfica aborigen presentada tanto para la isla como para la La Candelaria (Fig. 5 y 7), se sugiere que su incidencia en el proceso de extinción Selk'nam habría sido relativamente menor que la de otros factores. Por ejemplo, la concentración en la Misión San Rafael (Dawson) produjo una elevada mortandad por enfermedades (Belza, 1974:335; Garcia Moro, 1992; Martinic, 1973; Borrero, 2001:68). Asimismo, resta evaluar la influencia de La Candelaria en la dispersión de enfermedades entre las poblaciones naturales, considerando que se trataba de un establecimiento que permitía el constante intercambio con el resto de la isla, como se ha observado a lo largo de este trabajo.

Para distintos autores la desaparición de la etnia Selk'nam habría sido producto de un complejo desarrollo del que formaron parte diversos elementos, tales como las matanzas, la pérdida del territorio, la alteración en la apropiación de los recursos, los enfrentamientos intraétnicos, el asilo en las misiones, las presiones culturales y el mestizaje, entre otros. Según Borrero (2001:123), la causalidad circula de manera compleja a través de todos estos factores. Resulta muy difícil decidir el orden en el que actuaron y, en algún sentido, su importancia relativa. Trabajos como el aquí desarrollado guardan la intención de formular contribuciones a tales cuestionamientos.

Las fuentes empleadas son el recurso más detallado con que se cuenta para analizar el proceso de contacto en las misiones salesianas de 
Tierra del Fuego, aquí La Candelaria. Sin embargo, también contienen imprecisiones y omisiones; ello no impide obtener algunos conceptos importantes respecto del contacto interétnico, relativizando anteriores hipótesis y creando otras nuevas que induzcan a venideras vías de análisis.

\section{AGRADECIMIENTOS}

Se agradece especialmente al Padre J uan Ticó y al Padre Omar Álvarez, Misión La Candelaria quienes nos recibieron cordialmente y suministraron las fuentes utilizadas. A la Dra. Mónica Salemme y al Lic. Fernando Santiago, CADIC, y a la Secretaría de Turismo de la Provincia de Tierra del Fuego quienes colaboraron en la realización de la campaña 2005. A Patricia Palacio (Téc. CONICET) por su colaboración. Agradecemos las sugerencias realizadas por los evaluadores. A nuestras familias por su permanente apoyo. EI estudio es parte del proyecto Ecología Evolutiva Humana en Tierra del Fuego (PICT No 13889, 2005-2007) y el Convenio de Colaboración Instituto Canario de Bioantropología, Tenerife y Fac. de Cs. Sociales de la Univ. Nac. del Centro, Argentina.

\section{BIBLIOGRAFÍA}

BANDIERI, S. 2005. Historia de la Patagonia. Ed. Sudamericana. Buenos Aires.

BEILBY, J ., REED, J ., BAKER, J , WILSON, K., SANSBURY, M., ANTIC, R., y ROBINSON, P.C. 1990. Tuberculosis surveillance in the South Australian aboriginal community. Medical J ournal of Australia, 153 (3): 149-155.

BELZA, J. E. 1974. En la isla del fuego 10 Encuentros. Ed. Instituto de Investigaciones históricas de Tierra del Fuego. Buenos Aires.

BELZA, J. E. 1975. En la isla del Fuego 2o Colonización. Ed. Instituto de Investigaciones históricas de Tierra del Fuego. Buenos Aires.

BENENSON, A. S. 1992. El control de las enfermedades transmisibles en el hombre. Ed. Organización Panamericana de la Salud.

BORRERO, L. A. 1992. El registro arqueológico del Contacto: enfermedad y discontinuidad poblacional. Simposio Encuentro de Dos Culturas. Ed. Centro Cultural General San Martín. Buenos Aires.

BORRERO, L. A. 2001. Los Selk'nam (Onas). Ed. Galerna. Buenos Aires.

BRAUN MENENDEZ, A. 1939. Pequeña historia fueguina. Ed. Emecé. Buenos Aires.

BRAUN MENENDEZ, A. 1941.Ushuaia. Revista Geográfica Americana, 93: 395-399.

BRIDGES, T. 1886. El confín sur de la república. La Tierra del Fuego y sus habitantes. Boletín del Instituto Geo- gráfico argentino, 7: 200-212

BRUNO, C.1981a. Los salesianos y las hijas de María Auxiliadora en la Argentina. Tomo I. Ed. Instituto Salesiano de Artes Gráficas. Buenos Aires.

BRUNO, C.1981b. Los salesianos y las hijas de María Auxiliadora en la Argentina. Tomo II. Ed. Instituto Salesiano de Artes Gráficas. Buenos Aires.

BRUNO, C.1981c. Los salesianos y las hijas de María Auxiliadora en la Argentina. Tomo III. Ed. Instituto Salesiano de Artes Gráficas. Buenos Aires.

BUIKSTRA J . E. y UBILAKER D.H. (editors) 1994. Standards for data collection from human skeletal remains. Arkansas archeological survey research series $n \circ 44$. Arkansas.

CANADIAN LUNG ASSOCIATION. 2000. Canadian Tuberculosis Standars. 5 th edition. Ed. CLA. Canadá.

CANADIAN TUBERCULOSIS COMMITTEÉ. 2002. Tuberculosis in Canadian-born aboriginal peoples. Public Health Agency of Canada. Versión online: http:// www.phac-aspc.gc.ca/publicat/tbcbap-tbpac/ special_report_e.html\#top (última actualización: 2203-2002).

CHAPMAN, A.1998. Los Selk'nam. La vida de los onas. Ed. Emecé. Buenos Aires.

COIAZZI, A. 1997. Los indios del Archipiélago fueguino. Editorial Ateli. Punta Arenas.

DABBENE, R. 1904. Viaje a Tierra del Fuego y a la isla de los Estados. Boletín del Instituto Geográfico argentino XXI:3-78.

DANIEL, T.M. 1981. An Inmunochemist's view of the epidemiology of tuberculosis. En Prehistoric tuberculosis in the Americas. Buikstra, J.E. (eds.). Ed. Northwestern University Archaeological Program. Illinois.

DE AGOSTINI, A. 1956 Treinta años en Tierra del Fuego. Ed. Peuser. Buenos Aires.

EMPERAIRE J. y LAMMING, A. 1954. La desaparición de los últimos fueguinos. Revista Diógenes, 2 (8):4579.

FUGASSA, M.H. y GUICHON, R.A. 2004. Transición epidemiológica en Tierra del Fuego: el contacto indirecto y las enfermedades infecciosas entre 1520 y 1850. Magallania, 32: 99-113.

GARCIA MORO, C. 1992. Reconstrucción del proceso de extinción de los Selk'nam a través de los libros misionales. Anales del Instituto de la Patagonia, 21: 33-46.

GARCIA MORO, C., HERNANDEZ, M. y LALUEZA, C. 1997. Estimation of the optimum density of the Selk'nam from Tierra del Fuego: inferences about human dynamics in extreme environments. American J ournal of Human Biology, 9:699-708.

GUSINDE, M.1951. Hombres primitivos en la Tierra del Fuego (de investigador a compañero de tribu). Ed. Escuela de Estudios hispano-americanos de Sevilla.

GUSINDE, M.1982. Los Indios de Tierra del Fuego. Tomo I. Vol I. Ed. Centro Argentino de Etnología Americana. Buenos Aires.

JOHNSTON, W.D. 1993. Tuberculosis. En The Cambridge world history of human disease. Cambridge University Press. New York.

KUNIMOTO, D., SUTHERLAND, K., WOOLDRAGE, K., FANNING, A., CHUI, L., MANFREDA, J . y LONG, R. 2004. Transmission characteristics of tuberculosis in the foreign-born and the Canadian-born 
populations of Alberta, Canada. International J ournal of Tuberculosis Lung Disease, 8 (10): 12131220.

MARTINIC, M. 1973. Panorama de la colonización en Tierra del Fuego entre 1881-1900. Anales del Instituto de la Patagonia, 4:5-69.

MARTINIC, M. 1982. La tierra de los fuegos. Ed. Municipalidad de Porvenir. Magallanes.

MARTINIC, M. 1990. EI genocidio Selk'nam: nuevos antecedentes. Anales del Instituto de la Patagonia, 19: 23-28.

MARTINIC, M. 2003. Los últimos Selk'nam en Tierra del Fuego chilena. Magallania 31: 21-31.

MASSA, Lorenzo. 1945. Monografía de Magallanes. Setenta años de acción salesiana en el sur 1886-1946. Ed. Escuela Tipográfica del Instituto Don Bosco. Punta Arenas.
MASSONE, M., JACKSON, D. y PRIETO, A.1993. Perspectiva arqueológica de los Selk'nam. Ed. Centro de Investigaciones Diego Barros Arana. Santiago de Chile.

MASSONE, M. 1987. Los cazadores paleoindios de Tres Arroyos (Tierra del Fuego). Anales del Instituto de la Patagonia, 17: 47-60.

PAESA, P. R. 1976. Los indios de la patagonia y la acción salesiana. Suplemento Boletín Salesiano, 2: 4-36.

SHI-SHUNG, L. 2000. Differential Mortality in Colonial Taiwan (1895-1945). 19th International Congress of Historical Science, Oslo.

VYNNYCKY, E. y FINE, P.E.M. 1999. Interpreting the decline in tuberculosis: the role of secular trends in effective contact. International Journal of Epidemiology, 28: 327-334. 